\title{
PEDAGOGIA NO CONTEXTO DA POLÍTICA TERRITORIAL: UM ESTUDO DO PROCESSO EDUCATIVO DESENVOLVIDO NO COLEGIADO DE DESENVOLVIMENTO TERRITORIAL (CODETER) DO TERRITÓRIO DA CIDADANIA DO BAIXO TOCANTINS - PA.
}

\author{
Sara Corrêa DIAS ${ }^{1}$ \\ Núcleo de Extensão em Desenvolvimento Territorial (NEDET/BT). \\ saracdias@yahoo.com.br \\ Francinei Bentes TAVARES ${ }^{2}$ \\ Universidade Federal do Pará. \\ francinei@ufpa.br \\ Miqueias Freitas CALVI ${ }^{3}$ \\ Universidade Federal do Pará. \\ miqueiascalvi3@gmail.com
}

Resumo: Este estudo trata dos aspectos educativos desenvolvidos no Colegiado de Desenvolvimento Territorial (CODETER) do Baixo Tocantins (BT), com ênfase nas ações participativas engendradas pelas organizações da sociedade civil e do poder público, no âmbito da gestão social das políticas territoriais. A pesquisa teve como objetivo analisar a influência da participação dos movimentos sociais e das instituições públicas e suas contribuições para a organização política dos agentes sociais que atuam no CODETER. Os procedimentos metodológicos envolveram o uso de metodologias de base qualitativa, como entrevistas semiestruturadas, com a aplicação de questionários. A pesquisa permitiu concluir que o Colegiado encontra-se em uma situação de fragilidade no que diz respeito a participação e a gestão social das políticas públicas.

Palavras-chave: Colegiado Territorial, Participação, Baixo Tocantins.
Abstract: This study deals with the educational aspects developed in the Territorial Development Board (CODETER) Baixo Tocantins (BT), with emphasis on participatory actions engendered by civil society and the government, in the social management of territorial policies. The research aimed to analyze the influence of the participation of social movements and public institutions and their contributions to the political organization of social workers involved in CODETER. The methodological procedures involved the use of qualitative basic methodologies such as structured interviews, with questionnaires. The research concluded that the Board is in a fragile situation as regards participation and social management of public policies.

Keywords: Territorial Board, Participation. Baixo Tocantins.

\footnotetext{
${ }^{1}$ Graduada em Licenciatura Plena em Pedagogia, no Campus Universitário do Tocantins / Cametá (CUNTINS. Mestranda em Educação e Cultura, na Universidade Federal do Pará. Tem experiência na área da educação, movimentos sociais, administração e gestão escolar, estudos agrários e acordos de pesca.

2 Doutorado em Sociologia pela Universidade Federal do Rio Grande do Sul, Brasil(2012) Professor Adjunto I da Universidade Federal do Pará , Brasil.

3 Mestrado em Agriculturas Amazônicas pela Universidade Federal do Pará, Brasil(2009) Professor Titular da Universidade Federal do Pará, Brasil.
} 


\section{INTRODUÇÃO}

Este trabalho faz parte de um projeto de extensão universitária intitulado: "Monitoramento e avaliação de políticas públicas para gestão de territórios na Amazônia Paraense", coordenado pela Secretaria de Desenvolvimento Territorial do Ministério do Desenvolvimento Agrário (SDT / MDA) do Governo Federal. O estudo trata dos aspectos educativos desenvolvidos no CODETER do Baixo Tocantins ${ }^{4}$, com ênfase nas ações participativas engendradas pelas organizações da sociedade civil e do poder público, no âmbito da gestão social das políticas territoriais. Busca elucidar sobre os mecanismos que constituem o território e as características presentes nos debates e planejamentos institucionais.

A região do Baixo Tocantins é caracterizada por sua diversidade cultural e seus vastos recursos naturais, sendo que os movimentos sociais organizados se constituíram da luta pelos direitos das populações, de acesso não apenas a educação, saúde, lazer, mas às políticas públicas voltadas para o contexto rural.

Atualmente, essa região vem sendo palco de uma forte intervenção estatal através de políticas de apoio e Assistência Técnica e Extensão Rural e fomento a participação dos agricultores familiares, crédito, Programa de Apoio à Infraestrutura nos Territórios Rurais (PROINF), Programa de Aquisição de Alimento (PAA), Programa Nacional de Alimentação Escolar (PNAE), Educação do Campo (fortemente presente através do PRONATEC-Campo) e o Desenvolvimento Territorial. Esse apoio vem fortalecendo as lideranças rurais do BT e, sobretudo, o território como um todo por meio das formas de participação engendradas no Colegiado.

Os procedimentos metodológicos utilizados no desenvolvimento da pesquisa envolveram o uso de metodologias de base qualitativa, como entrevistas de roteiro semiestruturado, com a aplicação de questionários. Do total foram realizadas 10 (dez) entrevistas, sendo 06 (seis) com representantes da sociedade civil e 04 (quatro) do poder

\footnotetext{
${ }^{4} \mathrm{O}$ território do Baixo Tocantins está localizado na região Nordeste do Estado do Pará, abrangendo uma área de aproximadamente 36.024,20 Km², sendo composto por 11 municípios: Abaetetuba, Acará, Baião, Barcarena, Cametá, Igarapé-Miri, Limoeiro do Ajuru, Mocajuba, Moju, Oeiras do Pará e Tailândia.
}

MARGENS - Revista Interdisciplinar Versão Digital - ISSN: 1982-5374
10 Anos de Margens - Dossiê: Olhares para o campo... VOL.10. N. 15. Dez 2016. (p. 85-97) 
público. Estes sujeitos são considerados importantes por participarem da ação territorial e das discussões a cerca das políticas públicas do território.

As entrevistas foram realizadas a partir de agendamento prévio e no local de preferência dos informantes (sendo que algumas aconteceram durante os encontros e reuniões do colegiado), mas sempre de forma individual. A coleta de dados realizou-se no período de quatro meses (outubro a dezembro de 2015 e janeiro de 2016). Os dados foram obtidos por meio de registro e transcrições das entrevistas e dos materiais utilizados na pesquisa. Este trabalho consistiu na transcrição, leitura, sistematização e análise de todos os dados obtidos, organizando-os de acordo com as questões que nortearam a pesquisa.

\section{O CARÁTER EDUCATIVO DOS MOVIMENTOS SOCIAIS}

Desde as décadas de 1960 e 1970, os Movimentos Sociais vêm se constituindo decorrente de todo um processo organizado pelas classes populares em todo o Brasil. Com a institucionalização dos espaços de participação política (considerando que foram reconhecidos com a Constituição de 1988), principalmente a partir dos anos de 1980, a população que há muito tempo vinha lutando por direitos ainda não estabelecidos, começa a constituir, com o apoio da Igreja Católica, mais precisamente com o Movimento de Educação de Base (MEB) novos mecanismos de luta, estes embasados em valores e participação desenvolvida em ações sociais coletivas.

Através de suas lutas, sobretudo na área da educação, os movimentos sociais vêm constituindo historicamente formas organizativas de aprendizagem (quer nas ações voltadas para a construção de saberes e valores, quer na participação e formação política dos sujeitos), no sentido de possibilitar um aprendizado que emerge de um processo coletivo no qual de acordo com Arroyo (2003, p. 33) trazem um componente essencial para o pensar e fazer educativos, que é "reeducar-nos para por o foco nos sujeitos sociais em formação". Gohn (2006, p. 35) ainda acrescenta dizendo que:

[...] os movimentos pela educação têm caráter histórico, são processuais e ocorrem, portanto, dentro e fora de escolas e em outros espaços institucionais. As lutas pela educação envolvem a luta por direitos e são parte da construção da cidadania [...].

MARGENS - Revista Interdisciplinar Versão Digital - ISSN: 1982-5374
10 Anos de Margens - Dossiê: Olhares para o campo... VOL.10. N. 15. Dez 2016. (p. 85-97) 
A autora aponta que o processo educativo não se restringe apenas em canais institucionais escolares, mas também no campo não-formal, nas relações extra-formais, aquela que emana do povo, construída nas lutas dos movimentos sociais e edificada na práxis, e a partir de suas reflexões a referida autora identifica três dimensões onde isso ocorre, a saber: a dimensão da Organização Política, a dimensão da Cultura Política e a dimensão Espacial-Temporal (GOHN, 1994).

Compreende-se, que em sua essência, os movimentos sociais, ao longo da sua perpetuação, apontam um caráter educativo, não na perspectiva de aprendizagens descomprometidas com a transformação social, que podem emergir em conceitos esvaziados de significados e destituídos de valores. Mas caracterizam-se pelo caráter coletivo e dinâmico, socialmente organizado, como um movimento de base e de busca de transformação das situações de opressão sejam elas sociais, culturais, econômicas, políticas, raciais, educacionais, etc. Para Arroyo e Fernandes (1999, p. 14) “[...] o próprio movimento social é educativo, forma novos valores, nova cultura, provoca processos em que desde a criança ao adulto, novos seres humanos vão se constituindo".

Nesse sentido, no âmbito do CODETER do BT, a participação dos movimentos sociais nas discussões e tomada de decisões é de fundamental importância para a construção de conceitos e parcerias alicerçadas nas práticas, objetivos e demandas do território, uma vez que o colegiado está intimamente ligado às entidades representativas dos sujeitos no contexto territorial nos quais se inserem.

Nestes termos, a participação assume um caráter impulsionador que paulatinamente vai metaforizando as concepções e ações educativas em resultados concretos que beneficiam o território rural. Quando se cria formas participativas de aprendizagem dentro de uma organização social, se abre um caminho diverso de concepções e articulação processual, que ao mesmo tempo em que constrói o debate político, cria possibilidades de embate e resolução de problemas, ampliando os espaços de participação e tomada de decisões, o que será descrito adiante. 


\section{O COLEGIADO TERRITORIAL COMO ESPAÇO DE PARTICIPAÇÃO POLÍ́TICA.}

O Colegiado territorial em sua constituição e essência deve possibilitar a participação de todos os seus membros, buscando aprimorar metodologias que estimulem tal processo, sobretudo no âmbito das discussões, formulações e decisões políticas do território. Para isso, é necessária a criação de estratégias de identificação dos grupos, organizações e instituições, com a abordagem de temáticas delineadas, objetivos e interesses comuns voltados para as reais necessidades do território.

Constituída enquanto um fator de luta e engajamento social, a participação perpassa por inúmeros fatores que estão correlacionados com a dinâmica da sociedade vivenciada em cada período histórico. De acordo com Gohn (2011) a participação é histórica e assume diferentes significados dependendo do contexto em que é atribuída. Citando Carvalho (1995) Gohn (2011, p. 51) acrescenta que a participação política, estimulada por políticas públicas estatais, surge a partir da "“...] ideia da participação comunitária [...] no início deste século, como um componente ideológico e prático do movimento dos centros comunitários de saúde norte-americanos [...]".

Nesse sentido, a partir da década de 1980, a participação dos indivíduos nas discussões, elaboração de estratégias e de tomada de decisão começa a aparecer, com propostas associadas aos movimentos sociais populares. Assim, a participação era voltada para a busca de melhorias estruturais e dos "direitos sociais, econômicos e políticos dos setores populares" (GOHN 2011, p. 52). Porém, não se restringia apenas a esses setores, mas associava-se em objetivos e ações demandadas pela sociedade de modo geral. Gohn (2011, p. 16) ainda acrescenta que a participação é:

[...] uma lente que possibilita um olhar ampliado para a história [...]. No entendimento dos processos de participação da sociedade civil e sua presença nas políticas públicas nos conduz ao entendimento do processo de democratização da sociedade brasileira, o resgate dos processos de participação leva-nos, portanto, às lutas da sociedade por acesso aos direitos sociais e à cidadania [...].

MARGENS - Revista Interdisciplinar Versão Digital - ISSN: 1982-5374
10 Anos de Margens - Dossiê: Olhares para o campo... VOL.10. N. 15. Dez 2016. (p. 85-97) 
Todo esse aparato histórico contribuiu para que hoje o processo participativo seja um dos elementos essenciais de transformação socioeconômica, sendo ainda mais reforçado e vivenciado nas sociedades modernas. Tornando-se assim, um elemento potencial de diálogo, troca de conhecimentos e produção do saber, não somente associado à organização política dos trabalhadores, mas também às complexas e valorosas relações existentes entre a sociedade civil e o poder público.

No Colegiado territorial do BT, essas relações se inserem no seio do debate da política territorial. As ações trabalhadas e formuladas coletivamente e o constante embate entre a sociedade civil e o poder público possibilitaram a organização de metas e práticas estratégicas que, além de estarem alicerçadas em objetivos a serem alcançados, contribuíram e/ou contribuem para a formação política dos atores que estão envolvidos nesse processo.

\subsection{O Colegiado de Desenvolvimento Territorial - CODETER do Baixo Tocantins}

Os territórios rurais caracterizam-se como espaços de protagonismo e gestão social de políticas públicas, que foi concebido em 2003 pelo Programa Nacional de Desenvolvimento Sustentável de Territórios Rurais (PRONAT) sob a responsabilidade do Ministério de Desenvolvimento Agrário (MDA). O objetivo central era desenvolver a agricultura familiar, a partir de um enfoque territorial. Em 2008, o Programa Territórios da Cidadania (PTC), ampliou esse debate, articulando políticas públicas no espaço rural e incorporando outros municípios, como é o caso do Baixo Tocantins. Dentre as várias atribuições sobre o conceito de território, destaca-se que ele pode ser compreendido por uma acepção ampla como:

[...] um espaço físico, geograficamente definido, geralmente contínuo, compreendendo cidades e campos, caracterizados por critérios multidimensionais, tais como o ambiente, a economia, a sociedade, a cultura, a política e as instituições, e uma população, com grupos sociais relativamente distintos, que se relacionam interna e externamente por meio de processos específicos, onde se pode distinguir um ou mais elementos que indicam identidade e coesão social, cultural e territorial (BRASIL, 2005, p. 28).

Os colegiados territoriais surgem como um mecanismo de fortalecimento das discussões que envolvem os territórios e também ao fato de que "vinham preencher uma 
grande lacuna existente no meio rural, ou seja, a falta de espaços públicos de participação adequados à discussão e apropriação de políticas públicas, por parte dos grupos sociais não patronais e suas representações [...]" (LASA; DELGADO, 2013, p. 98). Os Colegiados são considerados espaços institucionalizados de participação e de legitimação da política pública, colocando-se nos processos de gestão social dos recursos federais destinados ao desenvolvimento rural (FREITAS et al 2012).

E como espaços institucionais de participação social determinam o estabelecimento de relações comunicativas constituídas em integração com a sociedade civil, provocando relações argumentativas que fundamentem o diálogo com representantes do governo. $\mathrm{O}$ aprendizado gerado pelo trabalho dos atores territoriais é afirmado como resultado das próprias discussões sobre os projetos e ações do território.

No Baixo Tocantins, o CODETER se constitui enquanto uma instância coletiva de debate sobre as questões produtivas e socioeconômicas ligadas ao Desenvolvimento Rural Sustentável do território. É um espaço democrático, paritário, constituído pelos segmentos governamental e da sociedade civil organizada. O Colegiado envolve os municípios de Abaetetuba, Acará, Barcarena, Baião, Cametá, Igarapé-Miri, Limoeiro de Ajuru, Moju, Mocajuba, Oeiras do Pará e Tailândia.

O CODETER é composto por representantes institucionais dos setores regionais, rural e urbano, e busca planejar ações de desenvolvimento sustentável e de integração de políticas públicas no âmbito dos municípios constituintes do Território, por meio do Programa Territórios da Cidadania, do Governo Federal. O colegiado é a institucionalidade territorial, que assume um papel importante para a condução e operacionalização da estratégia de desenvolvimento do território, além de possibilitar discussão a cerca das questões voltadas para a dinâmica de cada município, compreendendo suas diversidades socioambientais e culturais.

A estrutura de funcionamento do CODETER é formada pelo Plenário (instância máxima nas suas deliberações Ordinárias e Extraordinárias); o Núcleo Diretivo (nível decisório intermediário) é a instância gerencial dos programas e planos; a Secretaria Executiva, dentre as suas atribuições, compete auxiliar a coordenação na divulgação das 
resoluções formuladas e garantir a conservação dos documentos elaborados nas plenárias e outros encontros do colegiado; e por último o Núcleo Técnico, é o órgão auxiliar, interdisciplinar que apoia as atividades do CODETER, sobretudo na realização de estudos e execução de projetos que contribuam para a formação dos agentes de desenvolvimento territorial (conselheiros).

Dentre as atribuições do colegiado destacam-se "[...] a definição, a orientação, a negociação e o acordo entre as partes envolvidas na implementação de iniciativas e políticas públicas para o desenvolvimento rural do território [...]” (BRASIL, 2014, p. 3). São ações que envolvem todos os atores que participam do CODETER, principalmente no âmbito das discussões acerca das políticas que seriam mais bem implementadas no território, visando o seu desenvolvimento integral.

A Plenária é o órgão colegiado superior, que entre outras funções, compete o papel de deliberar e tomar as decisões estratégicas vinculadas ao processo de desenvolvimento territorial, cuja composição é feita de forma paritária, envolvendo a Sociedade Civil e o Poder Público. Sendo que no mínimo $50 \%$ das vagas sejam ocupadas por representantes ou entidades da sociedade civil organizada e legalmente constituída e no máximo $50 \%$ de representantes governamentais (dos Poderes Executivo, Legislativo e Judiciário) vinculados às discussões sobre o contexto rural sustentável, inclusive universidades, e outras instituições de pesquisa e extensão rural.

\section{AS APRENDIZAGENS INSTITUCIONAIS ADQUIRIDAS PELA SOCIEDADE CIVIL E O PODER PÚBLICO ATRAVÉS DA PARTICIPAÇÃo NO CODETER/BT.}

Por ser um espaço de interação social, de diálogo e produção de conhecimento, o Colegiado do Baixo Tocantins se constitui também como fonte de ricas aprendizagens pela própria dinâmica que apresenta. Essa formação institucional poderá contribuir para o aprimoramento das metas e propostas estabelecidas no seio das reflexões políticas e para a riqueza das discussões vivenciadas no interior da instituição. Entretanto, para que se tenha 
resultados qualitativos no que diz respeito a participação ativa no CODETER, as entidades representativas precisam trabalhar a formação política dos sujeitos que as compõem, de forma a amplificar as possibilidades de entendimento e empoderamento na resolução de problemas, o que nem sempre ocorre, conforme relata um dos entrevistados.

Em minha opinião, as entidades que participam dos trabalhos do CODETER não dedicam atenção à necessária formação de seus representantes. Que eu saiba, nenhuma entidade realiza algum tipo de formação especifica para a participação de seus representantes no Colegiado [...] (REPRESENTANTE DE ENTIDADE DA SOCIEDADE CIVIL).

Por mais que o CODETER por si só possibilite o conhecimento, o mesmo de acordo com o entrevistado proporciona poucas propostas de formação educativa voltadas para seus membros constituintes. As ações formativas estão muito aquém das expectativas e do que é necessário para o fortalecimento do colegiado, apontando-se por um viés educacional, através de momentos que oportunizem a aprendizagem de temas centrais e conceitos básicos para o entendimento do território como um todo, além da compreensão dos objetivos das políticas e programas de cunho governamental e suas implicações práticas, entre outras questões. Isso se confirma na fala de um dos entrevistados quando diz que:

O CODETER, que eu me lembre, não tem realizado, recentemente, atividades de formação de seus membros [...]. Isso se repercute no desempenho pífio do Colegiado, pois parte de seus membros não conhece suas atribuições, os conceitos básicos e os objetivos da política de desenvolvimento territorial (REPRESENTANTE DE ENTIDADE DA SOCIEDADE CIVIL).

A partir do relato do entrevistado, pode-se perceber a importância de ações de caráter formativo para a articulação das políticas territoriais que estão inseridas no contexto rural, haja vista que o conhecimento teórico-prático da ação poderá ampliar o arcabouço de possibilidades e tornar a política de mais fácil acesso aos agricultores.

Destaca-se que esse baixo índice de atividades educativas no CODETER, mostra a fragilidade a qual o território passa atualmente, associando-se também ao pouco interesse de algumas organizações (da sociedade civil e do poder público) em estarem participando e 
contribuindo com a dinâmica do colegiado. Esse déficit participativo de certa forma impede com que os atores tenham acesso às informações relevantes para a implementação das políticas públicas no território. Um dos entrevistados acrescenta dizendo que "estamos no momento de reflexão, pois existe um desânimo por parte de alguns membros do colegiado, a mobilização continua, existe um grupo que não desiste, sempre atuando" (Representante de entidade do poder público).

Observou-se que o colegiado do BT funciona como espaço de socialização de ideias e informações sobre ações e projetos que serão elaborados a nível territorial e que estão sendo desenvolvidos nos municípios. Nas reuniões do Colegiado, por exemplo, os representantes costumeiramente informam a respeito das realidades políticas, sociais e culturais de suas localidades, além das dificuldades que enfrentam na implementação de projetos.

As abordagens interativas promovidas por meio desta troca de informações contribuem para a constituição de laços intermunicipais que fortalecem as dinâmicas internas no colegiado. Além disso, nota-se, que por meio de questionamentos e indagações, os representantes dão contribuições aos projetos existentes nos municípios e a criação de outros projetos, seja em forma de apoio institucional de suas organizações ou por intermédio de sugestões para melhoria da execução do mesmo.

Essas iniciativas e formulações contextuais resultantes da relação entre sociedade civil e os órgãos governamentais no CODETER, cria métodos de aprendizagem que contribui significativamente para solidificar as metas e pautas de discussão do colegiado. Além disso, fortalece a luta por acesso às políticas para o meio rural, formando uma base cristalizada e ancorada em ideias e concepções comuns ao bem-estar social dos trabalhadores/as. As diferentes relações transformam as divergências em acordos, no qual todos têm o direito de participar e discutir as temáticas que são propostas. Destaca-se nesse processo, algumas dificuldades no campo do planejamento e implementação das políticas, como afirma um dos entrevistados:

A meu ver, o processo de planejamento do desenvolvimento territorial é um assunto extremamente complexo, que deve ser enfrentado com as devidas competências e com um alto nível de seriedade. Vários atores devem ser incluídos, envolvendo o setor privado, num processo continuado de negociação e identificação de prioridades [...] ou resultará na queda de

MARGENS - Revista Interdisciplinar Versão Digital - ISSN: 1982-5374
10 Anos de Margens - Dossiê: Olhares para o campo... VOL.10. N. 15. Dez 2016. (p. 85-97) 
interesse das organizações sociais e do poder público [...] (REPRESENTANTE DE ENTIDADE DA SOCIEDADE CIVIL).

O entrevistado aponta várias facetas que demonstram a fragilidade a qual passa o território do BT, fazendo-se necessário que o Colegiado a partir de sua construção política tome iniciativas que possam estar instituindo ações inovadoras de planejamento e funcionamento, no sentido de voltar a exercer sua função de articulador e propulsor de políticas públicas para o espaço rural. Além disso, "um grande investimento em formação e uma injeção de credibilidade são necessários para que o Colegiado volte a desenvolver seu papel de planejador dos rumos do desenvolvimento do território do Baixo Tocantins" (Representante de entidade da sociedade civil).

Por outro lado, quaisquer que sejam os problemas presentes no CODETER, os atores entrevistados apontam o fato de que a instituição constitui um grande avanço na concepção e construção de políticas públicas para âmbito rural. Além do contato maior com os problemas vivenciados no território, como afirma o entrevistado.

Em termos positivos, com certeza o CODETER proporcionou para a nossa instituição o contato com diferentes organizações, tanto do poder publico quanto da sociedade civil, e o conhecimento de temáticas e problemas que afetam o território, conteúdos aos quais não teria tido acesso sem participar dos trabalhos do Colegiado (REPRESETANTE DE ENTIDADE DA SOCIEDADE CIVIL).

Entre os elementos positivos do Colegiado, destacam-se na fala dos entrevistados: disponibilidade de informações para os agricultores familiares sobre as políticas e as ações dos governos estaduais, federais e municipais; compreensão da atitude e da visão de mundo de cada um dos atores, permitindo mudar as percepções sobre o contexto social; aprendizagem dos agricultores familiares a respeito do diálogo com o governo, entendendo as metas e os desafios de uma gestão social de políticas públicas; considerando como um espaço de debate e de definições de prioridades; a inclusão gradual de outros segmentos da sociedade, antes deixados à margem do debate das ações públicas (indígenas, mulheres, 
jovens, quilombolas, pescadores e outros), com poder de participação e voz nas tomadas das decisões.

Embora com participação tímida no colegiado territorial, como foi possível observar, cabe destacar o esforço de algumas instituições (da sociedade civil e do governo) no processo de desenvolvimento das atividades do CODETER, quer na operacionalização de demandas ou na mobilização dos atores para a participação dos encontros e plenárias. Essas instituições buscaram através do diálogo desenvolver estratégias de fortalecimento das ações presentes no território, procurando na medida do possível manter as discussões e o andamento das políticas voltadas para o meio rural.

\section{CONCLUSÃO}

A pesquisa permitiu concluir que o Colegiado de Desenvolvimento Territorial do Baixo Tocantins encontra-se em uma situação de fragilidade no que diz respeito a participação e a gestão social das políticas públicas, principalmente pelo fato do baixo índice participativo das entidades que compõem o CODETER. Todavia, destaca-se a importância do colegiado para o desenvolvimento socioeconômico do Baixo Tocantins, através de políticas de acesso aos programas governamentais e ao fomento as iniciativas dos agricultores familiares na gestão dos recursos ligados a agricultura familiar regional.

Foi possível observar na pesquisa, a realização de poucas ações educativas voltadas para a formação dos atores territoriais, na perspectiva de compreenderem suas reais funções no colegiado. Isso se vislumbrou na baixa participação dos atores territoriais seja nos debates e discussões ou na tomada de decisão, o que contribuiu também para a ausência de uma estratégia territorial que fomentasse as suas ações e fortalecesse os interesses dos participantes da sociedade civil e do poder público.

Para tanto, o CODETER/BT precisa ter um planejamento próprio com estratégia definida para sensibilizar os atores e motivar as entidades, pois a participação diferenciada dos variados atores possibilita a construção de uma gama de conhecimentos que articulam e enriquecem as discussões existentes na dinâmica do CODETER, o que pressupõe o 
envolvimento de um caráter educativo vivenciado no contexto das lutas do colegiado e suas diferentes formas de organização.

\section{REFERÊNCIAS BIBLIOGRÁFICAS}

ARROYO, M. G. PEDAGOGIA EM MOVIMENTO - o que temos a aprender dos Movimentos Sociais? Currículo sem Fronteiras, Belo Horizonte, v. 3, n. 1, p. 28-49, jan./jun. 2003.

ARROYO, M. G; FERNANDES, B. M. A educação básica e o movimento social do campo. Brasília-DF, 1999. (Coleção Por Uma Educação Básica Do Campo, nº 02). Disponível em: <file://C:/Users/Francinei1/Downloads/Livro\%20A\%20educacao\%20basica\%20e\%20o\%2 0movimento\%20social\%20do\%20campo\%20(1).pdf >. Acesso em: 21/01/2015.

BRASIL. Ministério do Desenvolvimento Agrário - MDA. Marco Referencial para Apoio ao Desenvolvimento de Territórios Rurais. Brasília-DF, 2005. (SÉRIE DOCUMENTOS INSTITUCIONAIS n. 02).

BRASIL. Ministério do Desenvolvimento Agrário - MDA. Referências para uma Estratégia de Desenvolvimento Rural Sustentável no Brasil. Brasília-DF, 2014. (SÉRIE DOCUMENTOS INSTITUCIONAIS n. 01).

FREITAS, A. F. de; FREITAS, A. F. de; DIAS, M. M. O colegiado de desenvolvimento territorial e a gestão social de políticas públicas: o caso do Território Serra do Brigadeiro, Minas Gerais. Rev. Adm. Pública. Rio de Janeiro 46(5): 1201-223 set./out. 2012.

GOHN, M. da G. Movimentos sociais e educação. 2a ed. São Paulo: Cortez, 1994 (Questões de nossa época, v. 5).

Educação não-formal, participação da sociedade civil e estruturas colegiadas nas escolas. Ensaio: aval. pol. pub. Educ. Rio de Janeiro, v. 14, n. 50, p. 27-38, jan./mar. 2006.

Conselhos gestores e participação sociopolítica. 4ª ed. São Paulo: Cortez, 2011 (Coleção questão de nossa época; v. 32).

LASA, C. G; DELGADO, N. Desenvolvimento Territorial e enfrentamento da pobreza rural no território de Irecê (BA). In: MIRANDA, C; TIBURCIO, B. Políticas de Desenvolvimento Territorial e Enfrentamento da Pobreza Rural no Brasil: estudos de casos. Brasília: IICA, 2013. (Série Desenvolvimento Rural Sustentável; v.20).

MARGENS - Revista Interdisciplinar

Versão Digital - ISSN: 1982-5374
10 Anos de Margens - Dossiê: Olhares para o campo... VOL.10. N. 15. Dez 2016. (p. 85-97) 